\section{LOW AND STARDARD DOSES OF SYNTHETIC ACTH IN THE ASSESSMENT OF ADRENAL FUNCTION OF CHILDREN WITH SEPTIC SHOCK}

R.G. Branco ${ }^{1,2}$, C.F. Amoretti ${ }^{3}$, C. Korb ${ }^{3}$, R. Camargo ${ }^{3}$, E. Jarmola ${ }^{3}$, F. Cabral ${ }^{3}$, J.P. Piva ${ }^{3}$, P.C.R. Garcia ${ }^{3}$, R.C. Tasker ${ }^{2}$

${ }^{1}$ Paediatric intensive Care Unit, Royal Brompton and Harefield NHS Trust, London, ${ }^{2}$ Paediatrics, Cambridge University, Cambridge, UK, ${ }^{3}$ Paediatric Intensive Care Unit, Hospital Sao Lucas da PUCRS, Porto Alegre, Brazil

Background and method: ACTH stimulation test is used for the diagnosis of adrenal insufficiency in sepsis, but the optimal dosage of ACTH is still debatable. We, therefore, compared the efficacy of low $\left(1 \mu \mathrm{g} / 1.73 \mathrm{~m}^{2}\right)$ and standard $\left(250 \mu \mathrm{g} / 1.73 \mathrm{~m}^{2}\right)$ dosages of $\mathrm{ACTH}$ in identifying adrenal insufficiency in children with septic shock.

Method:We evaluated 25 children admitted to PICU with catecholamine-dependent septic shock. Upon recruitment, a blood sample was collected for baseline cortisol determination. After an intravenous administration of low dose ACTH another blood sample was collected in 30 minutes for determination of cortisol response. Four hours after, a second intravenous ACTH stimulation test was performed, now using standard dose. Children were followed until PICU discharge.

Results: The mean baseline cortisol was $773 \pm 421 \mathrm{nmol} / \mathrm{L}$. Baseline cortisol was not different between survivors and non-survivors $(724 \pm 443$ vs $795 \pm 241, p=0.16)$. Mean peak cortisol after low dose ACTH stimulation was $1157 \pm 451 \mathrm{nmol} / \mathrm{L}$, with mean change from baseline of $458 \mathrm{nmol} / \mathrm{L}$. Both mean peak cortisol $(1160 \pm 445 \mathrm{nmol} / \mathrm{L})$ and mean change from baseline $(746 \pm 458 \mathrm{nmol} / \mathrm{L})$ were higher after standard dose ACTH stimulation $(p=0.045$ and $p<$ 0.01 , respectively). There was a good correlation between peak cortisol after low and standard dose ACTH stimulation tests $\left(r^{2}=0.58\right)$. Out of the 25 children in the study, $7(28 \%)$ had Al. All of these children could be identified using the low dose ACTH stimulation test, but only $3(43 \%)$ could be identified using the standard dose ACTH stimulation test $(p=$ 0.01) alone.

Conclusion: Low dose ACTH for adrenal stimulation identifies more children with $\mathrm{Al}$ when compared with the standard dose test.

\section{UTILITY OF THE WHO TEN QUESTIONS SCREEN FOR DISABILITY DETECTION IN A RURAL COMMUNITY-THE NORTH INDIAN EXPERIENCE}

\section{Kumar}

\author{
Ipswich Hospital, NHS Trust, Ipswich, UK
}

The utility of the WHO Ten Questions Screen (TQS) was studied in a rural community of North India. The study was done in three villages, in two phases. In phase 1, the TQS was administered to parents of children aged between 2 and 9 years, during a house-to-house survey. In phase 2, all children screened positive and a random sample of 110 screened negative were clinically evaluated in detail. The total population of the three villages was 5830 with 1763 children aged between 2 and 9 years. Seventy-six children were positive on the TQS, of these, 38 were found to have significant disability, 18 had protein energy malnutrition and 19 were found normal on clinical evaluation. All the 110 screen-negative children were normal. Significantly larger numbers of boys were positive on TQS as compared to girls [Odd Ratio (OR) 1.5]. The sensitivity of the TQS for significant disability was $100 \%$; the positive predictive value was $50 \%$ and was higher for boys than for girls. Of the $50 \%$ children classified as false positive $23 \%$ had mild delays due to malnutrition. The estimated prevalence of disability was $16 / 1000$. The TQS was found to be a sensitive tool for detection of significant disabilities among children 2-9 years of age. The low-positive predictive value would lead to over referrals but a large number of these children would benefit from medical attention.

\section{4}

COGNITIVE ABILITIES, QUALITY OF LIFE AND PSYCHOSOCIAL BURDEN IN LIVERTRANSPLANTED CHILDREN AND THEIR FAMILIES. THE PROJECT LIVE! ${ }^{R}$

\author{
T. Kaller ${ }^{1}$, N. Langguth ${ }^{1}$, B. Nashan ${ }^{2}$, \\ R. Ganschow ${ }^{3}$, K.H. Schulz ${ }^{4}$
}

${ }^{1}$ Center of Medical Psychology, Transplantation Psychology, ${ }^{2}$ Department of Hepatobiliary and Transplant Surgery, ${ }^{3}$ Department of Paediatrics, ${ }^{4}$ Center of Medical Psychology; Department of Hepatobiliary and Transplant Surgery, University Hospital Hamburg, Hamburg, Germany

Background and aims: Liver-transplanted children have an increased risk to develop 
Poster Presentation Abstracts

serious developmental problems and comorbid disorders. The project Live! ${ }^{\circledR}$ aims at establishing a psychosocial care for liver-transplanted children and their families.

Methods: Assessment of 169 families included: quality of life (KIDSCREEN-52), cognitive abilities (WISC), attention and executive functions (Test Battery for Attentional Performance, TAP), psychopathology (K-SADS-PL), and psychosocial burden in the families (Impact-on-Family Scale). At the time of transplantation, the mean age of children was 2.1 (SD 3.0) years. On average, they were examined 5.8 (SD 3.7) years after transplantation. Forty percent of children received a living donation.

Results: Quality of life in children aftertransplantation is inside the normal range. However, $40 \%$ of the sample showed psychiatric disorders. Cognitive abilities and several attention and executive function scales were significantly below average. Families with liver-transplanted children reported high psychological strain. Cognitive test performance was negatively correlated with the pre-operative duration of illness. Children who had received a living donation performed better in cognitive ability measures. Compliance problems were reported by $18 \%$ of the parents and $45 \%$ reported problems in Kindergarten or School. $51 \%$ of the families requested for (psychotherapeutic) support.

Conclusions: The results demonstrate that livertransplanted children are in urgent need for an early developmental screening after transplantation to prevent developmental deficits and to ensure children's social integration and mental wellbeing. Psychological support should be included in the standard routine of pre- and postoperative medical care of liver transplanted children and their families.

\section{5}

\section{KNOWLEDGE ABOUT CAR SAFETY SEAT USAGE IN FEMALE POPULATION IN ESKISEHIR CITY CENTER, TURKEY}

\author{
E.C. Dinleyici ${ }^{1}$, N. Tekin ${ }^{2}$, Z.A. Yargic ${ }^{1}$, \\ D. Arslantas ${ }^{3}$, A. Acikgoz ${ }^{4}$, F. Koc ${ }^{3}$
}

${ }^{1}$ Department of Pediatrics, ${ }^{2}$ Dept. of Pediatrics, Division of Neonatology, ${ }^{3}$ Department of Public Health, ${ }^{4}$ School of Health, Eskisehir Osmangazi

University Medical Faculty, Eskisehir, Turkey

Objective of the study is to get data about mothers' knowledge on car-safety seat usage with a detailed questionnaire.

Methods: A total of 1270 questionnaires were obtained from female population aged between 18 and 45 years in Eskisehir city center.

Results: 982 of them have $\geq 1$ child and 645 out of them have $\geq 1$ car. $24 \%$ of the participants' education levels are higher than high school. Only 65 participants have had a car-safety seat in their car when their child was born. However all of the participants have an idea about the results and number of deaths/year in our country due to car accidents. 1216 participants thought that the correct position is semi fowler.Only 76 out of 986 mothers have correct knowledge about the placement of carsafety seat and were not related with educational level $(p>0.05)$. Mothers between 25-35 years of age have more accurate knowledge according to the mothers ages between $18-25$ and $35-45$ years $(p<$ 0.01).60 out of 104 participants who have still a car-safety seat, can correctly use it. 18 of total participants know the rule that all infants should always ride rear-facing under one year of age.794 of the mother thought that feeding is possible while their children travel on the car-safety seat.

Conclusion: Traffic accidents are the leading cause of death and serious injury for children and adults in Turkey and car-safety seat usage is not a legitimate obligation. The results of this study can be used as a guide for law-makers and educational program directors about safe child travel.

\section{6}

\section{QUALITY OF LIFE, SELF-CONCEPT AND LOCUS OF CONTROL IN PAEDIATRIC HEART TRANSPLANT RECIPIENTS}

\author{
J. Wray ${ }^{1,2}$, C. Orrells ${ }^{1}$, H. Latch ${ }^{2}$, M. Burch ${ }^{2}$ \\ ${ }^{1}$ UCL Institute of Child Health, ${ }^{2}$ Great Ormond \\ Street Hospital for Children NHS Trust, \\ London, UK
}

Background and aims: Quality of life (QoL) is increasingly considered to be an essential health outcome measure in heart transplantation but few studies have addressed the relationship between QoL and psychological factors such as self-concept and locus of control. The aim of this study was to evaluate these factors in a group of heart transplant recipients and to compare them with scores of healthy children. 